\title{
Observed Abrupt Changes in Minimum and Maximum Temperatures in Jordan in the $20^{\text {th }}$ Century
}

\author{
Mahmoud M. Smadi \\ Department of Mathematics and Statistics, Jordan University of Science and Technology \\ P.O. Box 3030 Irbid, 22110, Jordan
}

\begin{abstract}
This study examines changes in annual and seasonal mean (minimum and maximum) temperatures variations in Jordan during the $20^{\text {th }}$ century. The analyses focus on the time series records at the Amman Airport Meteorological (AAM) station. The occurrence of abrupt changes and trends were examined using cumulative sum charts (CUSUM) and bootstrapping and the Mann-Kendall rank test. Statistically significant abrupt changes and trends have been detected. Major change points in the mean minimum (night-time) and mean maximum (day-time) temperatures occurred in 1957 and 1967, respectively. A minor change point in the annual mean maximum temperature also occurred in 1954, which is essential agreement with the detected change in minimum temperature. The analysis showed a significant warming trend after the years 1957 and 1967 for the minimum and maximum temperatures, respectively. The analysis of maximum temperatures shows a significant warming trend after the year 1967 for the summer season with a rate of temperature increase of $0.038^{\circ} \mathrm{C} /$ year. The analysis of minimum temperatures shows a significant warming trend after the year 1957 for all seasons. Temperature and rainfall data from other stations in the country have been considered and showed similar changes.
\end{abstract}

Key words: Jordan, abrupt changes, trends, time series, temperature minima, temperature maxima

\section{INTRODUCTION}

World-wide interest in global warming and climate change has led to numerous trend detection studies. A study using average reconstruction of land surface air temperature (LST) by Smith et al. ${ }^{[1]}$, indicated warming through the twentieth century and indicates warming of about $0.6^{\circ} \mathrm{C}$ over the twentieth century with an uncertainty estimate for the warming $\pm 0.3^{\circ} \mathrm{C}$, also the study indicates that there a gradual LST warming until about 1940, cooling (1940-1970) and a second warming trend begins about 1970. The successive periods of global warming, cooling and warming in the $20^{\text {th }}$ century show distinctive patterns of temperature change suggestive of roles for both climate forcing and dynamical variability ${ }^{[2]}$.

Various studies showed that the observed warming trend during past decades occurred mainly due to the increase in the minimum (night-time) temperatures rather than the maximum (day-time) temperatures. The increase in the minimum temperatures appeared mainly in USA, former USSR, China and Australia ${ }^{[3,4]}$. This has been related to several factors such as global warming, increased concentrations of anthropogenic green house gases, aerosols which exert cooling effects on the climate, increased cloud cover and urbanization $^{[5,6]}$.

In the Middle East, investigations of long-term variations and trends in temperature data are not receiving enough attention even though, these countries suffer serious environmental, agricultural and water resources problems. Cohen and Stanhill ${ }^{[7]}$ studied climate change in the Jordan Valley using rainfall, temperature and global irradiance records for three selected stations, namely, Kfar Blum, Degania and Sedom. According to their analysis, the minimum temperature trends are not consistent, but generally showed an increasing trend over most of the months. The increases in minimum temperature were least in early winter. Their results also showed statistically significant decreases in annual mean maximum temperatures. Also they conclude a marked decrease in irradiance and a significant reduction in atmospheric transmissivity in the region. Murat et al. ${ }^{[8]}$ studied the mean minimum and maximum temperatures for Turkey and found a cooling trend in maximum temperature and a warming trend in minimum temperature.

This study aims to characterize the occurrence of abrupt changes and trends in minimum and maximum time series temperatures in Jordan. The analysis in this work focuses on a strategic and historical station in Jordan, the AAM station, due to its reliability and length of the record. The temperature data obtained for the AAM station covers a period of 81 years; from 1923 to 2003. First screening of the data indicated no missing values. Temperature data from selected stations in Jordan were also selected and analyzed. The analyses of temperature fluctuations include annual and seasonal minimum (night-time) and maximum (day-time) temperatures. Cumulative sum charts (CUSUM) and 
bootstrapping were used to detect and locate any abrupt changes. The Mann-Kendall rank test was used to demonstrate existence of any possible trends.

Data used: The climate of Jordan is predominantly of the Mediterranean type. It is marked by sharp seasonal variations in both temperature and precipitation. Generally, hot dry summers and cool wet winter characterize the weathers in Jordan. The Amman Airport Meteorological (AAM) station was the main station in Jordan and was established in 1922, since British colonization of Jordan. The station lies in the eastern part of the capital city (Amman). The station elevation is $780 \mathrm{~m}$, above sea level (a. s. 1.) (with Latitude N $31^{\circ} 59^{\circ}$ and longitude E $35^{\circ} 59^{\circ}$. The mean annual rainfall and temperature are $275 \mathrm{~mm}$ and $12.3^{\circ} \mathrm{C}$, respectively, while the mean monthly evaporation is $51 \mathrm{~mm}$. The geographical location of Jordan and the AAM station provides a sign and indication about temperature changes and trends in the region. Different meteorological stations are scattered all over the country. However, in these stations minimum and maximum temperature records are available only after the year 1950 .

Examining the history of the AAM meteorological station records is necessary in order to rule out the trends and changes induced by site relocations and related changes. However, the lack of resources at the station has resulted in the unavailability of such information: very minor changes in site location within a small area of Amman Airport have been reported. It is advantageous to examine temperature and some related rainfall records from other stations in the country due to the deficiency of enough information about the history of AAM station. Table 1 reports details for these climatic stations.

\begin{tabular}{llllll} 
Table 1: & Stations locations & & \\
\hline Station & Elev. & Lat. N & & Long. E \\
\hline Irbid & 616 & 32 & 33 & 35 & 51 \\
Madaba & 785 & 31 & 43 & 35 & 48 \\
Mafraq & 683 & 32 & 22 & 36 & 15 \\
Dair-Alla & -224 & 31 & 13 & 35 & 37 \\
Al-Rwaished & 683 & 32 & 30 & 38 & 12 \\
Safawi & 674 & 32 & 12 & 37 & 08 \\
Amman Airport & 779 & 31 & 59 & 35 & 59 \\
Al-Raba & 920 & 31 & 16 & 35 & 45 \\
Shoubak & 1365 & 30 & 31 & 35 & 32 \\
Maan & 1069 & 30 & 10 & 35 & 47 \\
Aqaba & 51 & 29 & 33 & 35 & 00 \\
\hline
\end{tabular}

\section{MATERIALS AND METHODS}

Cumulative sum charts (CUSUM) and bootstrapping: This procedure was used by Taylor ${ }^{[9]}$ devised a procedure for performing change point analysis using cumulative sum charts (CUSUM) and bootstrapping. Let $\mathrm{X}_{1}, \mathrm{X}_{2}, \ldots, \mathrm{X}_{\mathrm{n}}$ represent the $n$ data points. The cumulative sums $\mathrm{S}_{0}, \mathrm{~S}_{1}, \ldots, \mathrm{S}_{\mathrm{n}}$ are calculated iteratively as follows:
1. Calculate the average

$$
\bar{X}=\frac{X_{1}+X_{2}+\ldots+X_{n}}{n}
$$

2. Let $S_{0}=0$.

3. Calculate $S_{i}$ recursively:

$$
\mathrm{S}_{\mathrm{i}}=\mathrm{S}_{\mathrm{i}-1}+\left(\mathrm{X}_{\mathrm{i}}-\overline{\mathrm{X}}\right), \quad \mathrm{i}=1,2, \ldots, \mathrm{n}
$$

A segment of the CUSUM chart with an increasing slope indicates a period where the values tend to be above the overall average. Likewise, a segment with a decreasing slope indicates a period of time where the values tend to be below the overall average. A sudden change in direction of the CUSUM indicates a sudden shift in the average. A period where the CUSUM chart follows a relatively horizontal path indicates a period where there is no change in the average. The confidence level can be determined by performing bootstrap analysis $^{[10]}$.

The above-mentioned control chart and the change point analysis are based on the assumption of independent errors around a possibly changing mean. When such techniques are applied to autoregressive data, erroneous conclusions can be obtained. However, shifts in the mean create autocorrelation between the observations which makes it difficult to distinguish the mean-shift data from the autoregressive data. A pattern test has been devised which can detect a violation of independent errors assumption and thus can reliably distinguish between these two important cases ${ }^{[11]}$. In this work, the software Change Point Analyzer was used and performs this test any time when analyzing any set of time ordered data ${ }^{[12]}$.

Mann-Kendall rank test: In parametric statistics, it is generally assumed that a sequence of observations is uncorrelated and normally distributed. Consequently, non-parametric statistics are applicable when one or more of these assumptions are not valid. The MannKendall rank statistic was used to determine the possible existence of a significant trend in the collected data over a period of time. The test is simple, robust and can cope with missing values and values below the detection limit. This test was found to be useful and widely used for detecting trends in climate and environmental sciences ${ }^{[8,10,13]}$.

The Mann-Kendall rank statistics is performed as illustrated in the following steps:

i. The original values of the series $x_{i}$ are replaced by their ranks $y_{i}$, arranged in ascending order.

ii. The magnitudes of $y_{\mathrm{i}}(i=1, \ldots, n)$ are compared with $\mathrm{y}_{\mathrm{j}}(j=1, \ldots, i-1)$. At each comparison, the number of cases $y_{i}>y_{j}$ is counted and denoted by $n_{i}$.

iii. A statistic $t$ is, therefore, defined as follows:

$\mathrm{t}=\sum_{\mathrm{i}=1}^{\mathrm{n}} \mathrm{n}_{\mathrm{i}}$ 
Am. J. Environ. Sci., 2 (3): 114-120, 2006

Table 2: Summary statistics and M-K statistics of minimum temperatures for the entire record and two sub-periods in AAM station

\begin{tabular}{|c|c|c|c|c|c|c|c|c|}
\hline & \multicolumn{2}{|c|}{$1923-2003$} & \multicolumn{3}{|c|}{$1923-1956$} & \multicolumn{3}{|c|}{$1957-2003$} \\
\hline & Slope & $\mathrm{M}-\mathrm{K}$ & Mean & Slope & M-K & Mean & Slope & M-K \\
\hline$\overline{\text { Annual }}$ & 0.009 & $1.78^{*}$ & 11.60 & 0.012 & 1.11 & 10.47 & 0.059 & $5.65^{* * *}$ \\
\hline Winter & -0.001 & 0.00 & 4.65 & 0.037 & 0.52 & 4.18 & 0.037 & $3.27^{* * *}$ \\
\hline Spring & 0.010 & 1.81 & 9.84 & 0.062 & 0.22 & 9.73 & 0.062 & $5.08^{* * *}$ \\
\hline Summer & 0.022 & $3.84^{* * *}$ & 17.81 & 0.078 & 1.11 & 18.14 & 0.078 & $6.35^{* * *}$ \\
\hline Autumn & 0.007 & 1.59 & 13.50 & 0.071 & 0.37 & 13.09 & 0.071 & $5.99^{* * * *}$ \\
\hline
\end{tabular}

Table 3: Results of change-point analysis on annual mean minimum temperature

\begin{tabular}{lllllll}
\hline Year & Confidence interval & Conf. level & From & To & Level \\
\hline 1935 & $(1932,1948)$ & $91 \%$ & 11.208 & 11.595 & 3 & \\
1957 & $(1956,1960)$ & $100 \%$ & 11.595 & 10.468 & 2 & \\
1979 & $(1975,1980)$ & $100 \%$ & 10.468 & 11.573 & 4 & \\
1994 & $(1994,1996)$ & $100 \%$ & 11.573 & 12.68 & 6 & $\square$ \\
\hline
\end{tabular}

iv. The distribution of the test statistic $t$, under the null hypothesis, is asymptotically normal with the following mean and variance,

$$
\mathrm{E}(\mathrm{t})=\frac{\mathrm{n}(\mathrm{n}-1)}{4}
$$

and

$$
\operatorname{var}(t)=\frac{n(n-1)(2 n+5)}{72}
$$

\section{RESULTS AND DISCUSSION}

Analyses of fluctuations in long term annual and seasonal mean minimum and maximum temperatures are presented. Analysis of seasonal data was performed only for AAM station. A season is defined as 3-month period, winter (December-February), spring (MarchMay), summer (June-August) and autumn (SeptemberNovember). The following asterisks will be frequently used in the result tables to denote statistical significance at different levels $(\alpha)$ : * for $\alpha=0.1, * *$ for $\alpha=0.05$ and $* * *$ for $\alpha=0.01$.

Minimum temperatures: The time series plot of the annual mean minimum temperature for AAM station is shown in Fig. 1. No statistical outliers were detected. The Figure shows steady rise in minimum temperature since the beginning of the record from 1923 to 1950 , then a decreasing (cooling) trend until late 1970's, followed by a further clear rise in minimum temperature from late 1970's to the end of the record in 2003. These results agree generally with the trend patterns of the global annual mean temperatures by Smith $^{[1]}$. Table 2 displays the regression slope estimates and Mann-Kendall (M-K) test statistics for the annual and the seasonal mean minimum temperatures for the entire period (1923-2003). A long-term warming trend is noted in the mean minimum temperatures for the annual and all seasonal series except that for winter. The warming trend is statistically significant for the annual mean minimum temperature at level of significance 0.1 ; also the warming trend is statistically significant during summer season with significance level 0.01. Generally, these results agree with the results previously described by Cohen and Stanhill ${ }^{[7]}$ for the Jordan Valley.

Table 3 shows the results of a change-point analysis for the annual mean minimum temperature for AAM. The table gives a level associated with each change; the level is an indication of the importance of the change. Using the Change Point Analyzer no departure from the independent error structure and no outlier's assumptions were found. The CUSUM chart is shown in Fig. 2. This analysis detects four changes which occurred in the years 1935, 1957, 1979 and 1994. The first and most important change is estimated to have occurred around 1957 with 100\% confidence level. Table 3 also indicates that the average annual mean minimum temperature of $11.6^{\circ} \mathrm{C}$ appeared prior to the first change while after the first the first change it was $10.5^{\circ} \mathrm{C}$. On the other hand, prior to the three changes in 1935, 1979 and 1994, the average annual mean minimum temperatures were $11.2,10.5^{\circ} \mathrm{C}$ and $11.6^{\circ} \mathrm{C}$, respectively, while after these changes, the temperatures were, $11.6,11.6$ and $12.7^{\circ} \mathrm{C}$, respectively (Table 3).

It is important to analyze the two sub-periods separately based on the most important change point detected (1957). The results revealed significant warming trend slope after 1957. The minimum temperature has increased by a rate of $0.059^{\circ} \mathrm{C} /$ year. Results for the seasonal mean minimum temperatures for AAM station are also given in Table 2. A statistically significant warming trend can be noticed after 1957 for all seasons.

The available annual mean minimum temperatures for other stations are available only after 1950, which makes a difficulty to compare other stations. Because of the relation between rainfall and temperature, annual total rainfall series and annual number of rain days series was analyzed in this work. The analysis shows insignificant changes for the total annual rainfall series and a significant change point in 1955 for the annual number of rain days. 


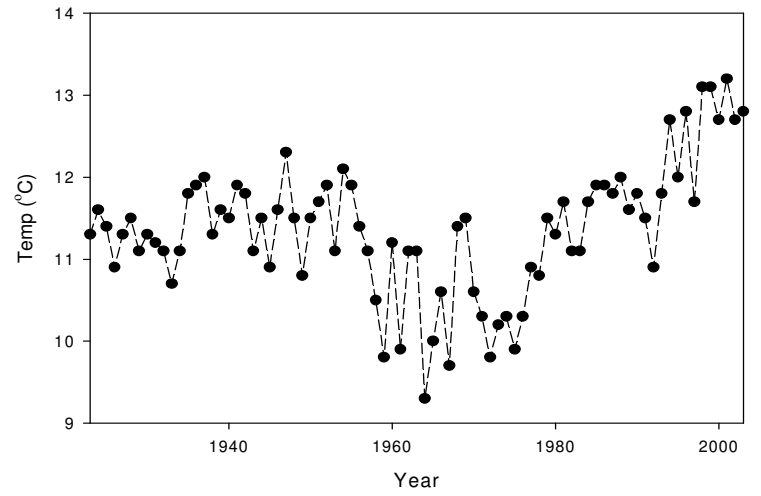

Fig. 1: The time series of AAM station annual mean minimum temperature

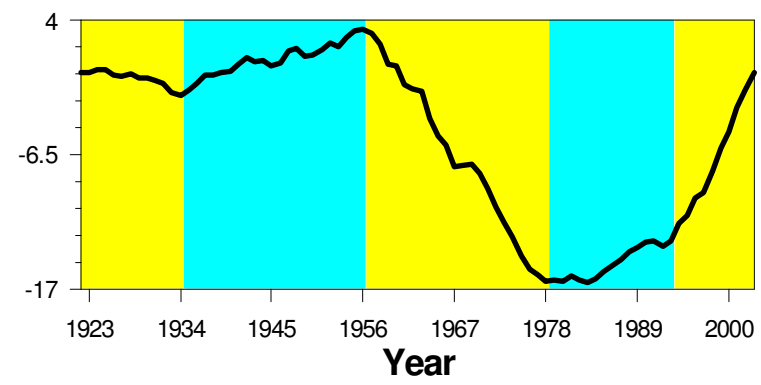

Fig. 2: CUSUM chart for the annual mean minimum temperature of AAM station

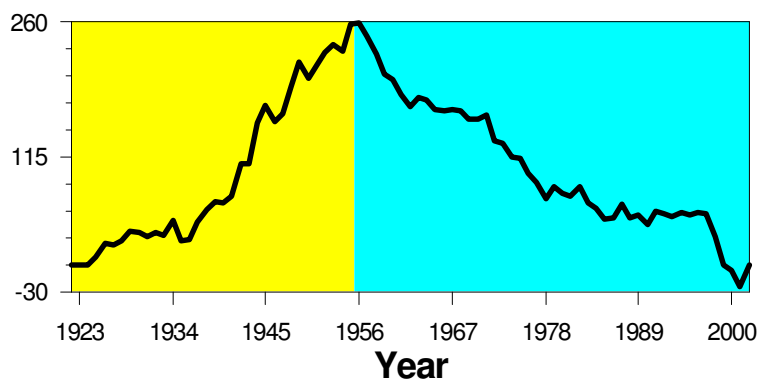

Fig. 3: CUSUM chart for the annual number of rain days of AMM station

The CUSUM chart is shown in Fig. 3 which supports the detected change point in the annual mean minimum temperature around the year 1957.

Maximum temperatures: The time series plot of the annual mean maximum temperature for AAM station is shown in Fig. 4. It shows a steady rise in maximum temperature since the beginning of the record, from 1923 to 1950, then a decreasing (cooling) trend till mid of 1970's, followed by a further rise in maximum temperature till the end of the record in 2003. These results agree generally with the trend patterns of the global annual mean temperatures by $\operatorname{Smith}^{[1]}$. Table 4 displays the regression slope estimates and MannKendall (M-K) test statistics for the annual and seasonal mean maximum temperatures for the entire period (1923-2003). A decreasing trend in the maximum

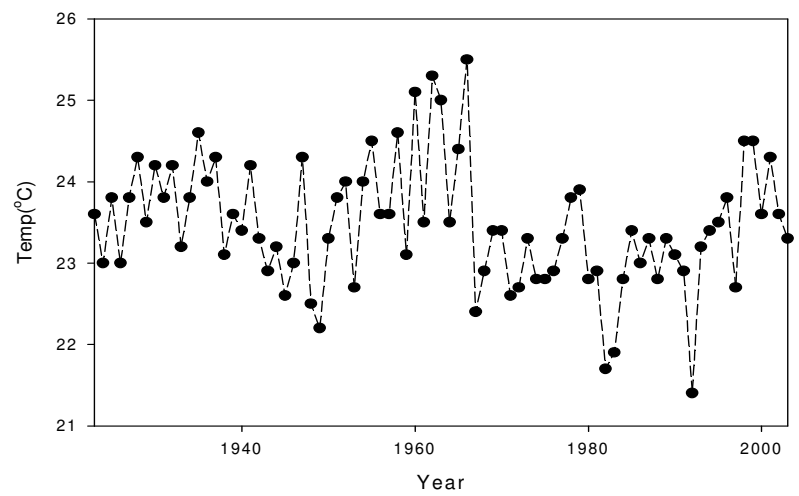

Fig. 4: The time series of AAM station annual mean maximum temperature

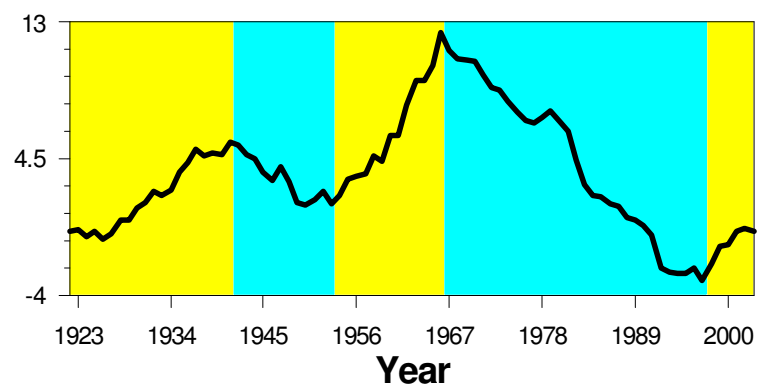

Fig. 5: CUSUM chart for the annual mean maximum temperature of AAM station

temperature can be noted for the annual and all seasonal series. This agrees with the results obtained by Cohen and Stanhill ${ }^{[7]}$ for the Jordan Valley which showed significant decrease in maximum temperatures. The rate of change in AAM station is -0.007 , where for Kfar Blam, Degania and Sedom stations, Cohen and Stanhill (1996) found $-0.035^{\circ} \mathrm{C},-0.024^{\circ} \mathrm{C}$ and $-0.018^{\circ} \mathrm{C}$, respectively.

Table 5 shows the results of a change-point analysis for the annual mean maximum temperature for AAM. Using the Change Point Analyzer software, no departure from any of the assumptions was found. The CUSUM chart is shown in Fig. 5. The analysis detects four changes which occurred in 1942, 1954, 1967 and 1998. The first and most important change point is estimated to have occurred around 1967 with 100\% confidence level. Prior to 1967 average annual mean maximum temperature was found to $24.3^{\circ} \mathrm{C}$ while after the first change it was $23^{\circ} \mathrm{C}$ (Table 5). The change point occurred in 1954 with confidence level agrees with the detected change point in the annual mean minimum temperature which was occurred in 1955.

The two sub-periods were analyzed separately based on the most important detected change point which occurred in 1967. The analysis demonstrates a warming trend in the first period and significant warming trend in the second period. Results for the seasonal maximum temperatures are also given in Table 4. The results detect a warming trend for all seasons before and after the change point. 
Am. J. Environ. Sci., 2 (3): 114-120, 2006

Table 4: Summary statistics and M-K statistics of maximum temperatures for the entire record and two sub-periods in AAM station

\begin{tabular}{|c|c|c|c|c|c|c|c|c|}
\hline & \multicolumn{2}{|c|}{$1923-2003$} & \multicolumn{3}{|c|}{ 1923-1966 } & \multicolumn{3}{|c|}{$1967-2003$} \\
\hline & Slope & M-K & Mean & Slope & M-K & Mean & Slope & M-K \\
\hline Annual & -0.007 & $-2.19^{* * *}$ & 23.748 & 0.016 & 0.99 & 23.132 & 0.023 & $2.17^{* * \pi}$ \\
\hline Winter & -0.004 & -0.12 & 13.708 & 0.028 & 1.58 & 13.205 & 0.012 & 0.71 \\
\hline Spring & -0.007 & -1.61 & 22.740 & -0.014 & -0.99 & 22.381 & 0.019 & $1.71^{*}$ \\
\hline Summer & -0.003 & -0.55 & 32.005 & 0.027 & $2.49^{* * *}$ & 31.406 & 0.038 & $2.48^{* * *}$ \\
\hline Autumn & -0.013 & $-3.01^{* *}$ & 26.412 & 0.004 & -0.14 & 25.618 & 0.013 & 0.71 \\
\hline
\end{tabular}

Table 5: Results of change-point analysis on annual mean maximum temperature

\begin{tabular}{lllllll}
\hline Year & Confidence interval & Conf. level & From & To & Level & \\
\hline 1942 & $(1935,1950)$ & $96 \%$ & 23.758 & 23.150 & 3 & \\
1954 & $(1951,1960)$ & $98 \%$ & 23.150 & 24.285 & 4 & \\
1967 & $(1963,1968)$ & $100 \%$ & 24.285 & 22.971 & 1 & \\
1998 & $(1992,2001)$ & $95 \%$ & 22.971 & 23.967 & 2 & 1 \\
\hline
\end{tabular}

Table 6: The mean maximum temperatures for the years 1966 and 1967 for different stations

\begin{tabular}{llcc}
\hline \multicolumn{3}{l}{ Mean annual maximum temperatures } & \\
\hline Station & 1966 & 1967 & Difference \\
\hline Amman & 25.5 & 22.4 & 3.1 \\
Maan & 25.5 & 22.9 & 2.6 \\
Irbid & 23.7 & 21.8 & 1.9 \\
Dair-Alla & 30.9 & 28.4 & 2.5 \\
Mafraq & 24.4 & 22.2 & 2.2 \\
Aqaba & 32.2 & 30.4 & 1.8 \\
\hline
\end{tabular}

Table 7: The total annual rainfall for the years 1966 and 1967 for different stations

Annual total rainfalls

\begin{tabular}{lccc}
\hline Station & $1965 / 1966$ & $1966 / 1967$ & Difference \\
\hline Amman & 219 & 459 & 239 \\
Madaba & 226 & 447 & 221 \\
Irbid & 398 & 754 & 356 \\
Dair-Alla & 210 & 441 & 231 \\
Mafraq & 144 & 261 & 117 \\
Shoubak & 185 & 380 & 195 \\
Al-Rwaished & 52 & 92 & 40 \\
Safawi & 68 & 105 & 37 \\
Al-Raba & 270 & 365 & 95 \\
\hline
\end{tabular}

Usually, the main sources for abrupt changes in climate data include station relocations, changes in observation times, methods used to calculate daily means, changes in gauged locations, changes in instruments, increased urbanized area and global warming $^{[13]}$. Another factor that could lead to climate changes is change in atmospheric circulation. The large-scale structure of the atmospheric circulation varies from year to year and region to region. Most of the studies deal with general patterns and trends of atmospheric circulations in the region. Thus, concerning abrupt changes, it would be advantageous to compare the results with other rural stations to see whether such changes are similar and of equal strengths.

Results from other stations: The available temperature records for other stations in Jordan are quite short and generally cover the last forty to fifty years only.

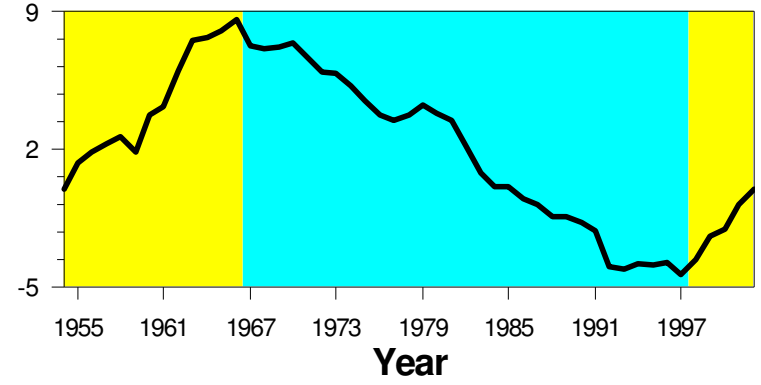

Fig. 6: CUSUM chart for the annual mean maximum temperature of Irbid station

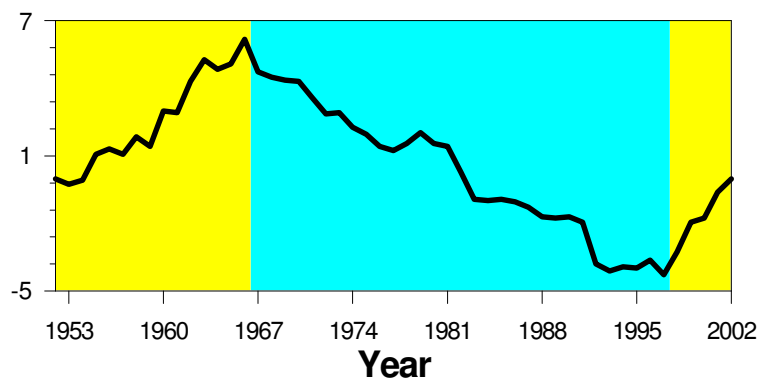

Fig. 7: CUSUM chart for the annual mean maximum temperature of Dair-Alla station

Maximum and minimum temperature records for two stations, Irbid and Dair-Alla are available only after the year 1955. Since the change point occurred in 1967, then it is not possible to make a comparison based on complete record lengths similar to that of the AAM station. However, it is possible to investigate the change point which occurred in 1967 in two ways; first study this change in the mean annual maximum temperatures only for the years 1966 and 1967 for different stations in the country, then the two seasonal total rainfalls in $1965 / 1966$ and 1966/1967 for different stations were also considered. Also analysis of the available annual mean maximum temperature records for Irbid and DairAlla stations was investigated using the data after 1955; which covers the detected change point in 1967.

The change point in the mean annual maximum temperatures was studied only for the two years 1966 
and 1967. The mean annual maximum temperatures of AAM station for the years 1966 and 1967 were found to be $25.5^{\circ} \mathrm{C}$ and $22.4^{\circ} \mathrm{C}$, respectively. Thus, a decrease of $3.1^{\circ} \mathrm{C}$ in the temperature occurred during these two subsequent years. The annual mean maximum temperature data for the years 1966 and 1967 for different stations in Jordan are shown in Table 6 and reveal similar remarkable changes. The nearest main station in neighboring courtiers is Damascus Airport station in Damascus, Syria. The mean annual maximum temperatures for the years 1966 and 1967 for Damascus Airport station were found to be $25.8^{\circ} \mathrm{C}$ and $23.3^{\circ} \mathrm{C}$, respectively. Thus a decrease of $2.5^{\circ} \mathrm{C}$ in the temperature occurred during these two subsequent years, which is in agreement with the magnitude of maximum temperature decrease in AAM station.

Because of the relation between temperature and rainfall, it would be also useful to investigate the total annual rainfall in Amman station and other stations for the years 1965/1966 and 1966/1967. The total annual rainfall for the years 1965/1966 and 1966/1967 for different stations in Jordan are also shown in Table 7. It is seen that the total annual rainfall in 1966/1967 is twice as large as that in 1965/1966 for most of the stations. Thus, it is expected that this regional sharp increase in the total annual rainfall resulted in the decrease in the temperature rates.

The annual mean maximum temperatures were also considered for Irbid station during the period 19552003 and for Dair-Alla station during the period 1953 2003. Analysis of the annual mean maximum temperature for Irbid and Dair-Alla stations shows two change points in 1967 and 1998 for the two stations respectively, with confidence levels $100 \%$. Using the Change Point Analyzer software, no departure from any of the assumptions was found. The CUSUM charts for Irbid and Dair-Alla stations are shown in Fig. 6 and 7, respectively. These results support and agree with the detected change point in annual mean maximum temperature in 1967 for AAM station.

The remarkable changes in maximum temperature and rainfalls for the years 1966 and 1967 for different stations and the detected changes in the annual mean maximum temperature for Irbid and Dair-Alla stations supports the results from AAM station. Thus, the 1967 change point in maximum temperatures is regional in scale than station specific.

The trends and changes detected in this work suggest synoptic changes in the region. Cohen and Stanhill's ${ }^{[7]}$ indicated a significant reduction in atmospheric transmissivity occurred in this region. They explained this possibly by the increased emissions of anthropogenic aerosols from upwind industrialized coastal region of Israel and of Europe.

\section{CONCLUSION}

The following concluding remarks can be outlined based on the results described in this work:

* Statistically significant change points in the mean minimum (night-time) temperature and mean maximum (day-time) temperature occurred in 1957 and 1967, respectively. Another change point in the annual maximum temperature also occurred in mid 1950.

* The analysis of minimum temperatures showed significant warming trend after the change point in 1957 for the annual and all seasonal series.

* Analysis of maximum temperatures reveals a warming trend for annual, spring, summer and autumn in the two sub-periods. The warming trend after 1967 for the summer seasons is statistically significant with a rate of increase of $0.038^{\circ} \mathrm{C} /$ year.

* Change points in temperature and rainfall data from other stations in Jordan are similar to those detected in the records at AAM station.

* It is worth mentioning that the results of this work can be considered as only partially conclusive. Further research should examine numerous long series of meteorological data available in Middle East.

\section{REFERENCES}

1. Smith, T.M. and W.R. Reynolds, 2005. A global merged land-air-sea surface temperature reconstruction based on historical observations (1980-1997). J. Climate, 18: 2021-2036.

2. Hansen, J.E., R. Ruedy, M. Sato, M. Imhoff, W. Lawrence, D. Easterling and T. Karl, 2001. A closer look at United States and global surface temperature change. J. Geophysics. Res., 106: 23947-23963.

3. Folland, C.K., T.R. Karl, N. Nicholls, B.S. Nyenzi, D.E. Parker and K.Y. Vinnikov, 1992. Observed climate variability and change', Climate Change. The Supplementary Report to the Intergovernmental Panel on Climate Change Scientific Assessment, Cambridge University Press, Cambridge, pp: 135-170.

4. Karl, T.R., G. Kukla, V.N. Razuvayev, M.J. Changery, R.G. Quayle, R.R. Heim, D.R. Easterling and C.B. Fu, 1991. Global warming evidence for asymmetric diurnal temperature change. Geophys. Res. Lett., 18: 2253-2256.

5. Balling, R.C., 1992. The heated debate: Greenhouse predictions versus climate reality. Pacific Research Institute for Public Policy, San Francisco, pp: 1955.

6. Englehart, P.J. and A.D. Douglas, 2003. Urbanization and seasonal temperature trends: Observational evidence from a data-sparse part of North America. Intl. J. Climatol., 23: 10. 
7. Cohen, S. and G. Stahill, 1996. Contemporary climate change in the Jordan valley. J. Appl. Meteorol., 35: 1051-1058.

8. Murat, T., M.S. Utku and K. Gonul, 1996. Observed changes in maximum and minimum temperatures in Turkey. Intl. J. Climatol., 16: 436477.

9. Taylor, W., 2000a. Change-point analysis: A powerful new tool for detecting changes. http://www.variation.com/cpa/tech/changepoint. html.

10. Sneyers, R., 1990. On the statistical analysis of series of observations. WMO Technical Note 143. WMO No. 415, TP-103, Geneva, World Meteorological Organization, pp: 192.
11. Taylor, W., 2000b. A pattern test for distinguishing between autoregressive and mean-shifted data. http://www.variation.com/ $\mathrm{cpa} / \mathrm{tech} / \mathrm{changepoint.html.}$

12. Taylor, W., 2000c. Change-Point Analyzer 2.3 software package. Taylor Enterprises, Libertyville, Illinois. http://www.variation.com/cpa

13. Kadiolgu, M., 1997 . Trends in surface air temperature data over Turkey. Intl. J. Climatol., 17: 511-520. 